\title{
Characterization of immunization secondary analyses using demographic and health surveys (DHS) and multiple indicator cluster surveys (MICS), 2006-2018
}

Yue Huang ${ }^{1,2}$ (D) and M. Carolina Danovaro-Holliday ${ }^{1 *}$

\begin{abstract}
Background: Infant immunization coverage worldwide has plateaued at about 85\%. Using existing survey data to conduct analyses beyond estimating coverage may help immunization programmes better tailor strategies to reach un- and under-immunized children. The Demographic and Health Survey (DHS) and the Multiple Indicators Cluster Survey (MICS), routinely conducted in low and middle-income countries (LMICS), collect immunization data, yet vaccination coverage is often the only indicator reported and used. We conducted a review of published immunization-related analyses to characterize and quantify immunization secondary analyses done using DHS and MICS databases.

Methods: We conducted a systematic search of the literature, of immunization-related secondary analyses from DHS or MICS published between 2006 and August 2018. We searched 15 electronic databases without language restrictions. For the articles included, relevant information was extracted and analyzed to summarize the characteristics of immunization-related secondary analyses. Results are presented following the PRISMA guidelines.

Results: Among 1411 papers identified, 115 met our eligibility criteria; additionally, one article was supplemented by the Pan American Health Organization. The majority were published since 2012 (77.6\%), and most (68.9\%) had a first or corresponding author affiliated with institutions in high-income countries (as opposed to LMICs where these surveys are conducted). The median delay between survey implementation and publication of the secondary analysis was 5.4 years, with papers with authors affiliated to institutions in LMIC having a longer median publication delay $(p<0.001)$. Over $80 \%$ of the published analyses looked at factors associated with a specific vaccine or with full immunization. Quality proxies, such as reporting percent of immunization data from cards vs recall; occurrence and handling of missing data; whether survey analyses were weighted; and listing of potential biases or limitations of the original survey or analyses, were infrequently mentioned.

(Continued on next page)
\end{abstract}

\footnotetext{
*Correspondence: danovaroc@who.int

'Department of Immunization, Immunization, Analytics and Insights (IAI),

Vaccines and Biologicals (IVB), World Health Organization (WHO), 1211

Geneva, Switzerland

Full list of author information is available at the end of the article
}

C C The Author(s). 2021 Open Access This article is licensed under a Creative Commons Attribution 4.0 International License, which permits use, sharing, adaptation, distribution and reproduction in any medium or format, as long as you give appropriate credit to the original author(s) and the source, provide a link to the Creative Commons licence, and indicate if changes were made. The images or other third party material in this article are included in the article's Creative Commons licence, unless indicated otherwise in a credit line to the material. If material is not included in the article's Creative Commons licence and your intended use is not permitted by statutory regulation or exceeds the permitted use, you will need to obtain permission directly from the copyright holder. To view a copy of this licence, visit http://creativecommons.org/licenses/by/4.0/ The Creative Commons Public Domain Dedication waiver (http://creativecommons.org/publicdomain/zero/1.0/) applies to the data made available in this article, unless otherwise stated in a credit line to the data. 
(Continued from previous page)

Conclusion: Our review suggests that more needs to be done to increase the increase the utilization of existing DHS and MICS datasets and improve the quality of the analyses to inform immunization programmes. This would include increasing the proportion of analyses done in LMICS, reducing the time lag between survey implementation and publication of additional analyses, and including more qualitative information about the survey in the publications to better interpret the results.

Keywords: DHS, MICS, Immunization coverage, Secondary analysis, Survey

\section{Background}

In past decades, great progress has been made in expanding the reach of immunization programme and introducing new vaccine $s[1-3]$. However, vaccinepreventable diseases (VPD) remain a significant cause of morbidity and mortalit y[4, 5].

Several initiatives have allied countries and immunization stakeholders towards reaching more people and preventing more vaccine-preventable diseases (VPDs). The Global Immunization Vision and Strategy 2006-2015 (GIVS )[6], then the Decade of Vaccines' Global Vaccine Action Plan (GVAP )[4], and soon the Immunization Agenda 2030 (IA2030 )[7], have guided efforts of achieving the vision of delivering universal access to immunization. Yet, coverage levels worldwide have plateaued at about $85 \%$ for 3 doses of diphtheria-tetanuspertussis vaccine (DTP3) and coverage gaps persist between countries, as well as within countrie s[8]. Thus, better understanding immunization program performance can help immunization programmes better tailor strategies to reach un- and under-immunized children [4].

Vaccine coverage (percentage of target population vaccinated) is a major indicator for immunization programme performance at the local, national, regional and global levels. It is used to target resources and identify areas requiring special attention, and is a core indicator for access to basic health service $s[9]$. Estimates of immunization coverage generally come from several sources, including administrative systems and registries and from different household survey $\mathrm{s}[6]$. Household surveys are frequently used to complement administrative data, and in some cases as the primary measurement of vaccination coverage. Oftentimes, it is thought that household surveys can give the more accurate and precise estimates, although they have the disadvantage that they cannot provide timely enough information for program planning, and can be subject to several biase s[10-13]. The Expanded Programme on Immunization (EPI) cluster surve $y[14]$, the United Nations International Children's Emergency Fund (UNICEF) Multiple Indicator Cluster Survey (MICS) [15] and the Demographic and Health Survey (DHS )[16] are the three main household surveys used to obtain vaccination coverage.
DHS and MICS almost always include immunizationrelated questions and report coverage indicators. These coverage estimates are used at the global level to inform the World Health Organization (WHO) and UNICEF National Estimates of Immunization Coverage (WUENIC )[3] and to assess progress by other immunization partners like Gavi, the Vaccine Alliance [17]. Nevertheless, it is unclear how much the national immunization programs of countries where these surveys are implemented use DHS and MICS results, and especially whether secondary analyses on immunization are done, and if so, whether they are used to inform immunization program planning. To answer the first question, we conducted a review and characterization of immunizationrelated secondary analyses published in the literature between 2006, the year that GIVS was launched [6], and 2018.

\section{Methods}

\section{DHS and MICS availability}

We extracted information about DHS and MICS surveys done and availability of those survey databases (as they are needed to conduct secondary analyses) from their respective websites.

\section{Literature search}

We searched articles, published between 2006 and August 2018, in 15 electronic bibliographic or full-text databases without language restrictions, including comprehensive databases from low and middle-income countries (LMICs) (Table 1).

The searching strategy was: full text search of (DHS OR MICS OR "demographic and health survey" OR "demographic and health surveys" OR "demographic health survey" OR "demographic health surveys" OR "demographic \& health survey" OR "demographic \& health surveys" OR "multiple indicator cluster survey" OR "multiple indicator cluster surveys"). For databases with available MESH search, searching of ("Immunization"[Mesh] OR "Vaccination"[Mesh]) was combined. Otherwise, title and abstract searching of (Immun* OR Vaccin*) was done.

To avoid missing articles, we searched PubMed and PMC (PubMed Center) separately. For the Web of 
Table 1 Database searching results

\begin{tabular}{|c|c|c|c|}
\hline Database & $\begin{array}{l}\text { Type of } \\
\text { database }\end{array}$ & Characteristic & Result \\
\hline $\begin{array}{l}\text { Web of science (Web of science } \\
\text { core collection) }\end{array}$ & Bibliographic & Comprehensive multiple databases. & 487 \\
\hline PubMed & Bibliographic & Primarily the MEDLINE database. & 168 \\
\hline PMC & Full-text & Publicly accessible full-text database. & 241 \\
\hline $\begin{array}{l}\text { The Institutional Repository for } \\
\text { Information Sharing (IRIS) }\end{array}$ & Full-text & $\begin{array}{l}\text { The digital library of WHO's published material and technical information in full text } \\
\text { produced since 1948. Its content is freely accessible and searchable in the six official } \\
\text { languages (Arabic, Chinese, English, French, Russian \& Spanish). }\end{array}$ & 147 \\
\hline $\begin{array}{l}\text { Index Medicus for South-East Asia } \\
\text { Region (IMSEAR) }\end{array}$ & Bibliographic & $\begin{array}{l}\text { A database of articles published in selected journals within the WHO South-East Asia } \\
\text { Region. }\end{array}$ & 114 \\
\hline $\begin{array}{l}\text { Joanna Briggs Institute EBP } \\
\text { Database }\end{array}$ & Full-text & $\begin{array}{l}\text { Published by the Joanna Briggs Institute (JBI),a leading provider of evidence-based } \\
\text { information. }\end{array}$ & 91 \\
\hline CINAHL & Bibliographic & Database with journal articles about nursing, allied health, biomedicine and healthcare. & 37 \\
\hline $\begin{array}{l}\text { BLDS Index to development } \\
\text { studies }\end{array}$ & Bibliographic & Europe's most comprehensive research collection on development issues. & 37 \\
\hline $\begin{array}{l}\text { Directory of Open Access } \\
\text { Journals Search }\end{array}$ & Bibliographic & $\begin{array}{l}\text { Independent database contains ca. 12,000 open access journals covering all areas of } \\
\text { science, technology, medicine, social science and humanities. }\end{array}$ & 28 \\
\hline Popline & Bibliographic & $\begin{array}{l}\text { Contains the world's most comprehensive collection of population, family planning and } \\
\text { related reproductive health and development literature. }\end{array}$ & 26 \\
\hline Informit Health Collection & Full-text & $\begin{array}{l}\text { An extensive range of authoritative subject-based databases featuring coverage of Aus- } \\
\text { tralian and international information resources. }\end{array}$ & 25 \\
\hline $\begin{array}{l}\text { Western Pacific Region Index } \\
\text { Medicus (WPRIM) }\end{array}$ & Bibliographic & $\begin{array}{l}\text { Medical and health journals published in Member States of the WHO Western Pacific } \\
\text { Region. }\end{array}$ & 5 \\
\hline $\begin{array}{l}\text { LILACS (Latin Am. \& Carib. Center } \\
\text { on Health Sci Info) }\end{array}$ & Bibliographic & Bibliographic database in the Health Sciences in Latin America and the Caribbean. & 4 \\
\hline Cochrane & $\begin{array}{l}\text { Bibliographic/ } \\
\text { full-text }\end{array}$ & $\begin{array}{l}\text { A collection of databases in medicine and other healthcare specialties provided by } \\
\text { Cochrane and other organizations. At its core is the collection of Cochrane Reviews, a } \\
\text { database of systematic reviews and meta-analyses. }\end{array}$ & 1 \\
\hline African Journals online & Full-text & The world's largest online library of peer-reviewed, African-published scholarly journals. & 0 \\
\hline
\end{tabular}

Science, we conducted both topic search and cited work search. All the searches were conducted under the technical guidance of the WHO librarian. The strategies were adapted to searching characteristics of each database. Staff from WHO regional offices were contacted to further identify missing articles.

The study protocol was submitted to PROSPERO. PROSPERO concluded that our study was a literature review with a systematic search, as opposed to a systematic literature review.

\section{Inclusion and exclusion criteria}

The inclusion criteria were: 1) papers published on or after 2006; 2) the study was a secondary analysis from DHS or MICS (sub-national MICS were not excluded); and 3) the main topic in the study was immunization. All the articles identified were imported into Endnote for systematical assessment. The lead author $(\mathrm{YH})$ independently conducted the initial literature screening. For the articles for which it was unclear if they met the inclusion criteria, the senior author (MCD-H) evaluated them and made the final decision regarding inclusion.

\section{Analyses}

For the articles included, the information listed below was extracted and analysed:
1) Metrics related to the publication:

a. Affiliation: for each article, the countries of all authors (based on their reported affiliations), and countries of first and correspondent authors were listed separately and analysed further. The countries were classified into high-income countries or LMICs according to 2018 World Bank classification [18].

b. The year of survey conduction (last year if DHS or MICS expanded over two calendar years)

c. The year of publication of the article.

d. The population analysed (e.g., children aged 12-23 months, women of childbearing age).

2) Main content of the publication:

a. Vaccine(s) included in the survey analysis. 
b. Outcomes: classification as complete or full immunization, vaccination with a specific vaccine(s) (e.g., measles-containing vaccine (MCV), diphtheria, tetanus and pertussis (DTP) vaccine, polio vaccine, Bacille Calmette-Guerin (BCG) vaccine, rotavirus vaccine, tetanus toxoid, hepatitis B vaccine, and so on), partial or incomplete immunization, and never vaccinated. If an article included multiple outcomes and various vaccines, they were all included and listed.

c. Types of analyses done: these included exploring factors associated with the outcome; inequalities in vaccination, such socio-economic and geographic variability; timeliness (considered as having received particular vaccines within a certain timeframe of the recommended age); coverage trends; and "others", such as supplementary immunization activities (SIA), mapping of immunization coverage, missed opportunities for vaccination (MOV), comparison of coverage estimates from multiple data sources, estimation of "effective vaccination coverage" using cross-sectional surveys combined with administrative data, immunization population targets, etc.

d. Methodological approaches used for the analyses.

3) Inclusion of information related to "quality" in the article:

a. Whether the study imputed missing data.

b. Whether the study described how persons without documented vaccination evidence (i.e., without cards) were handled. c. Whether the study included percentage of documented vaccination seen for the target group of the survey.

d. Whether the survey analysis was weighted.

e. Whether the article listed potential biases in the original survey.

f. Whether the article discussed potential limitations of the survey and/or the analysis.

g. Whether the article included recommendations based on the findings, and if so, whether these recommendations met SMART criteria (specific, measurable, attainable, relevant, timebound).

Chi-square test or Fisher's exact test was used to analyse the difference of the distribution of variables in different groups. All statistical analyses were performed using SPSS (24).

\section{Results}

As of August 2018, 308 standard DHS had been conducted (with 22 DHS ongoing at the time of the first writing in December 2018) in 91 low- and middleincome countries (LMICs) since 1985. Similarly, 352 MICS had also been done (with 60 not yet available) in 113 LMICs since 1993 (supplements 1,2) [19]. Regarding data publicly available, $94.1 \%(269 / 286)$ of DHS and 67.1\% (196/292) of MICS datasets were available.

Searches in 15 database identified a total of $1411 \mathrm{pa}-$ pers, of which 229 passed title, abstract and key words content screening; 115 were eligible for our study [8, 20-133]. One additional article [134] was supplemented by the Pan American Health Organization (PAHO), serving as the WHO regional office for the Americas (Fig. 1). Thus, a total of 116 articles were included (supplement 3).

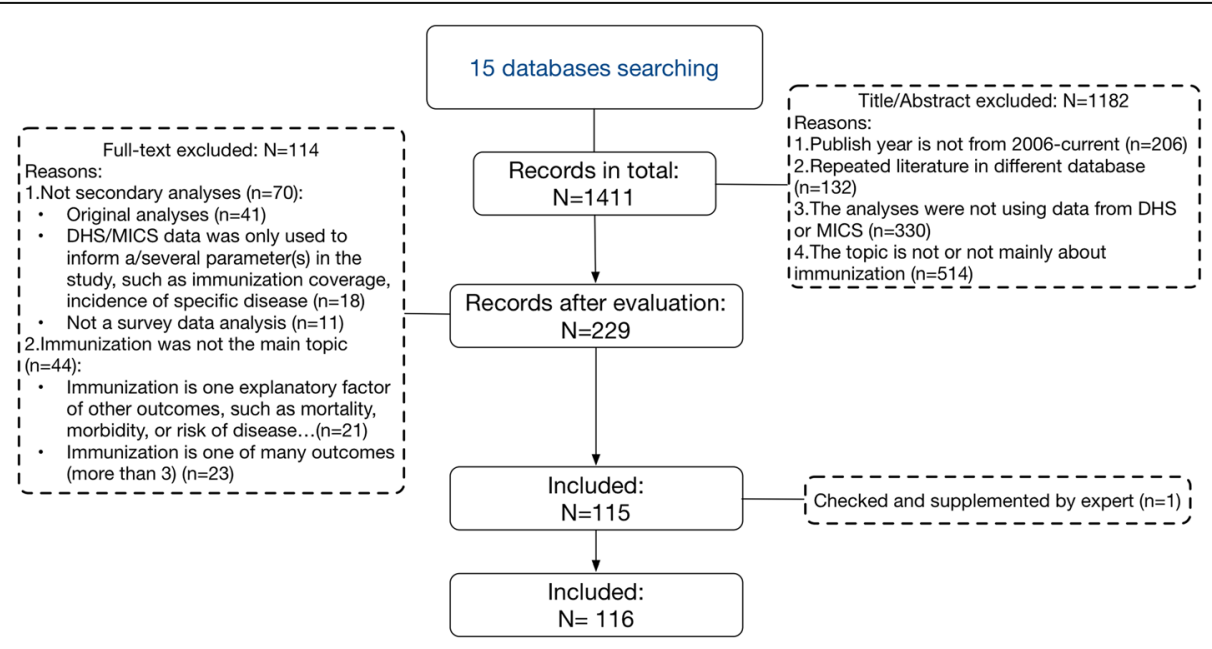

Fig. 1 Article screening diagram 
Table 2 Summary of included secondary analyses

\begin{tabular}{|c|c|c|c|}
\hline \multirow[t]{2}{*}{ Variables } & \multirow[t]{2}{*}{ Group } & \multicolumn{2}{|c|}{ Total $(N=116)$} \\
\hline & & $\mathrm{N}$ & $\%$ \\
\hline \multicolumn{4}{|l|}{ Publication metric } \\
\hline \multirow[t]{2}{*}{ Publish time period } & $2006-2011$ & 26 & 22.4 \\
\hline & 2012- August 2018 & 90 & 77.6 \\
\hline \multirow[t]{2}{*}{ Country of affiliations ${ }^{a}$} & High income & 80 & 68.9 \\
\hline & Low-middle income & 36 & 31.0 \\
\hline \multirow[t]{2}{*}{ Country analyzed } & Multiple countries & 37 & 31.9 \\
\hline & Single country & 79 & 68.1 \\
\hline \multirow[t]{2}{*}{ Affiliations match with survey countries ${ }^{b}$} & Yes & 38 & 48.1 \\
\hline & No & 41 & 51.9 \\
\hline \multirow[t]{2}{*}{ Survey year (last year) } & before 2011 & 84 & 72.4 \\
\hline & 2012-2018 & 32 & 27.6 \\
\hline \multirow[t]{3}{*}{ Publication delay } & Mean (SD) & $5.4(2.6)$ & \\
\hline & Within 5 years & 66 & 56.9 \\
\hline & More than 5 years & 50 & 43.1 \\
\hline \multicolumn{4}{|l|}{ Analyses content } \\
\hline \multirow[t]{3}{*}{ Survey types } & DHS & 100 & 86.2 \\
\hline & MICS & 7 & 6.0 \\
\hline & Both & 9 & 7.8 \\
\hline \multirow[t]{5}{*}{ Outcomes } & Specific immunization & 55 & 41.7 \\
\hline & Complete/full immunization & 53 & 40.2 \\
\hline & Partial or incomplete immunization & 12 & 9.4 \\
\hline & Never vaccinated & 11 & 8.3 \\
\hline & Other ${ }^{c}$ & 1 & 0.8 \\
\hline \multirow[t]{5}{*}{ Type of analysis } & Factors associated & 77 & 55.4 \\
\hline & Inequalities & 21 & 15.1 \\
\hline & Timeliness & 12 & 8.6 \\
\hline & Trends & 16 & 11.5 \\
\hline & Others & 13 & 9.4 \\
\hline \multicolumn{4}{|l|}{ Proxies for "quality" } \\
\hline \multirow[t]{4}{*}{ How persons without documented vaccination were handled } & Caregiver recall used & 86 & 74.1 \\
\hline & Recall excluded & 12 & 10.3 \\
\hline & Not mentioned & 17 & 14.6 \\
\hline & From other sources $^{d}$ & 1 & 0.9 \\
\hline \multirow[t]{2}{*}{ Percentage of documented vaccination seen } & Mentioned & 36 & 31.0 \\
\hline & No mentioned & 80 & 69.0 \\
\hline \multirow[t]{3}{*}{ Weighted analysis } & Yes & 67 & 57.8 \\
\hline & No & 4 & 3.4 \\
\hline & Not mentioned & 45 & 38.8 \\
\hline \multirow[t]{2}{*}{ Potential survey biases } & Listed & 54 & 46.6 \\
\hline & Not listed & 62 & 53.4 \\
\hline \multirow[t]{2}{*}{ Limitation(s) of secondary analyses } & Listed & 89 & 76.7 \\
\hline & Not listed & 27 & 23.3 \\
\hline
\end{tabular}

${ }^{a}$ The affiliations of first and corresponding authors separately counted; most of them (110/116) were from the same affiliation or income-level country. For those with first and corresponding author had a different affiliation (6/116), the higher income-level was used for classification

${ }^{b}$ Only secondary analyses using survey data from single country are included here (i.e., multi-country analyses exclude from this row)

"The one outcome listed as "other" was on knowledge about Human Papilloma Virus (HPV) vaccine

Information from administrative activities (e.g., vaccination records kept by health facilities), censuses, and vital registration systems was referred 
Of the 116 articles included, 90 (77.6\%) were published on or after 2012 and 84 (72.4\%) analyses used data from a survey conducted before 2011; 66 (56.9\%) analyses published within 5 years of the survey, with an average delay of 5.4 years $(\mathrm{SD}=2.6)$ (Table 2). Publication of secondary immunization analyses increased overtime (Fig. 2). Regarding author affiliation, most, 80 (68.9\%), of the first/corresponding authors were from high-income countries, 41 had a first or corresponding authors from the survey country, and 53 analyses had at least one of authors from the survey country. Most, 79 (68.1\%), analyses used survey data from single country, and of those, only $38(48.1 \%)$ had an author with an affiliation in that country. Nearly half of analyses conducted by highincome country used data from multiple countries.

Most articles, 100 (86.2\%), only used DHS data; 55 (41.7\%) focused on a specific vaccine and $53(40.2 \%)$ focused on complete or full immunization; 77 (55.4\%) and 21 (15.1\%) focused on determinants of vaccination and immunization coverage inequalities, respectively. Of the 21 studies that focused on immunization inequalities, 16 focused on socioeconomic inequalities, and 3 studies on gender-related inequalities; one study focused on geographical inequality, and one focused on both urbanrural residency and gender inequality. As per acknowledging survey or study limitations, 80 (69.0\%) did not mention the percentage of card/health records seen; 17 (14.6\%) did not mention how persons without documented vaccination were handled; 45 (38.8\%) did not mention whether the analyses was weighted; $62(53.4 \%)$ did not mention any potential biases; and 27(23.3\%) did not mention limitations of the analyses (Table 2). There was a significant difference on specifying how persons without documented vaccination were handled between main authors from LMICs (66.7\%) compared to those from high-income countries $(93.8 \%)$.
To understand any trends of immunization secondary analyses, we categorized the articles by publication year (before or after 2012, the year GVAP was endorsed by the World Health Assembly). The percentage of secondary analyses mentioning potential bias and limitations increased from 23.1 to $53.3 \%$ and 50.0 to $84.4 \%$, respectively. Other characteristic of immunization secondary analyses did not change significantly before and after 2012.

Figure 3 shows the distribution of immunization outcomes used of the secondary analyses included. Among all studies, 55 (41.7\%) focused on specific vaccines, with measles-containing vaccines (MCV) (32.7\%), diphtheria, tetanus and pertussis containing vaccines (DTP) (21.2\%), and polio vaccines $(20.2 \%)$ being the most frequent. 53 (40.2\%) focused on complete or full immunization, mostly defined as having received one dose of BCG and three doses of DTP and one MCV dose (38 of the 53, $71.7 \%)$.

Figure 4 shows the distribution of affiliation countries, the top three countries contributing most of the published studies, with a first or corresponding author from that country, included the United States (US), India and the United Kingdom (UK), with 35, 15, and 12 publications, respectively. Compared with high-income countries, analyses whose main authors had a LMIC affiliation were more likely be for a single country $(P<0.001)$, to have a longer time lag between survey and publication $>5$ years $(P<0.001)$, focus more on complete immunization $(P=0.003)$, and were less likely to include information on how persons without documented evidence of vaccination were handled $(P<0.001)$. No significant differences were found for other characteristic like publication year, survey type, type of analysis, mention of potential biases and the other proxies for quality (Table 3).

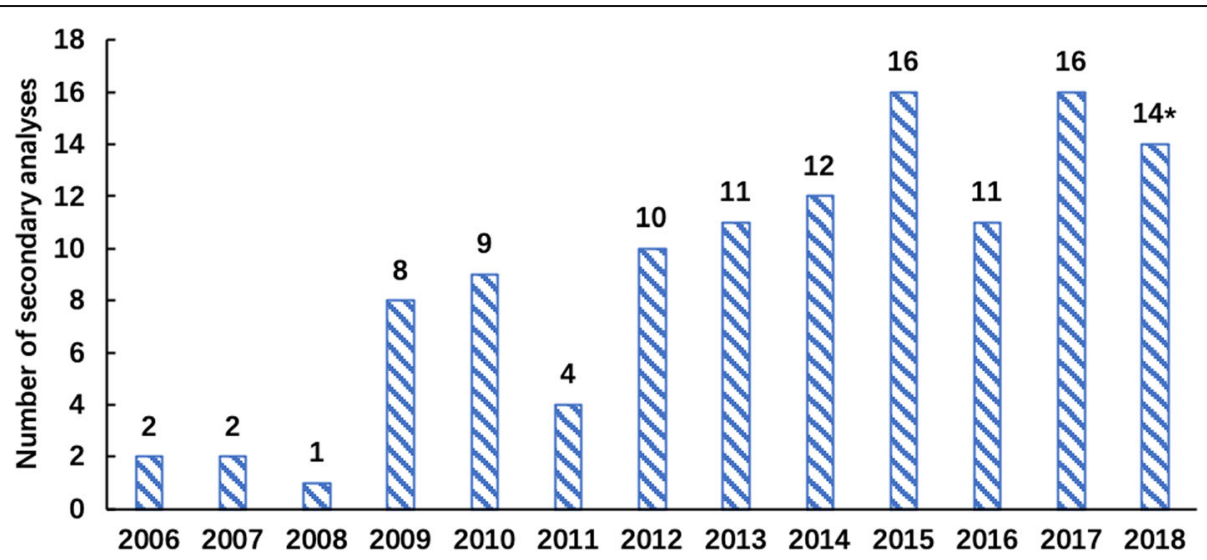

Fig. 2 Distribution of publishing year: * Only included secondary analyses published before August 2018 

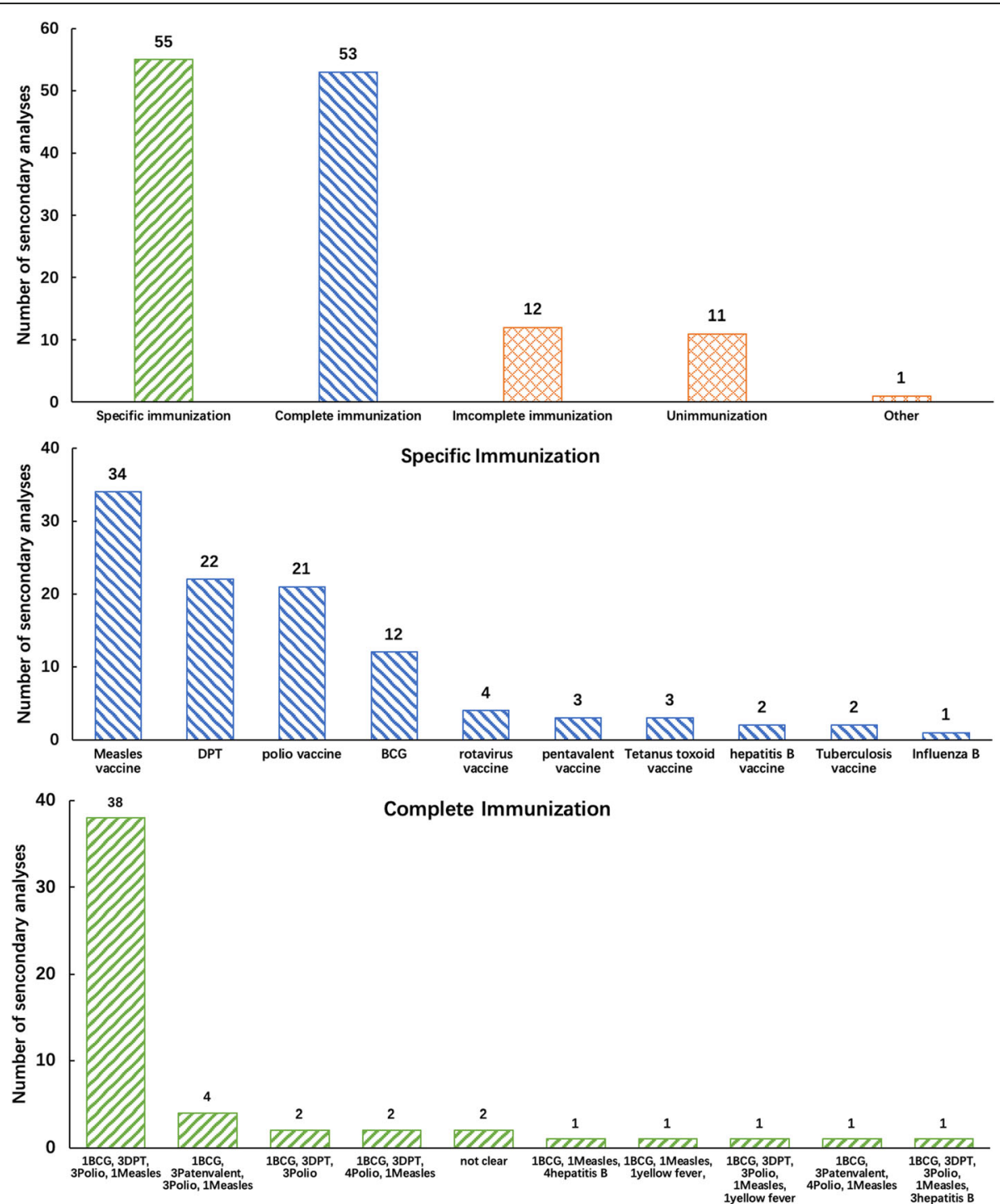

Fig. 3 Distribution of immunization outcomes: For articles that analysed more than 1 specific immunization, all of them have been listed. Complete immunization was defined as receiving all recommended primary vaccine doses by a defined age. The third part in the figure presented the definition of complete immunization used in the different studies. Incomplete immunization was defined as not completing a set of recommended vaccine doses by a defined age. Specific immunization was defined as immunization of one type of vaccine

\section{Discussion}

In our literature review, we analysed the immunization secondary analyses using DHS or MICS data since 2006 in order to better understand to what extent the DHS and MICS immunization data has been utilized beyond the coverage indicators included in the standard DHS and MICS reports. We also explored what vaccination issues were most looked at and whether some metrics related to "quality" were being included in these articles. We identified 116 published immunization secondary analyses using data from DHS and MICS, with over 3 out of 4 being published after 2012. The endorsement of GVAP by the World Health Assembly in 2012 may have been factor for the increase in secondary immunization analyses from multipurpose household surveys.

Interestingly, many more secondary analyses have used DHS data, as opposed to MICS, suggesting that the longer history of DHS database standardization and sharing may be a factor, but other factors may exist. Given that now more MICS surveys are being conducted, including sub-national surveys in many countries, it is possible that this difference will disappear going forward.

Most of the secondary immunization analyses focused on complete or full immunization, or in coverage with specific vaccines, and explored factors associated with these outcomes. Ideally, to make results more useful to 


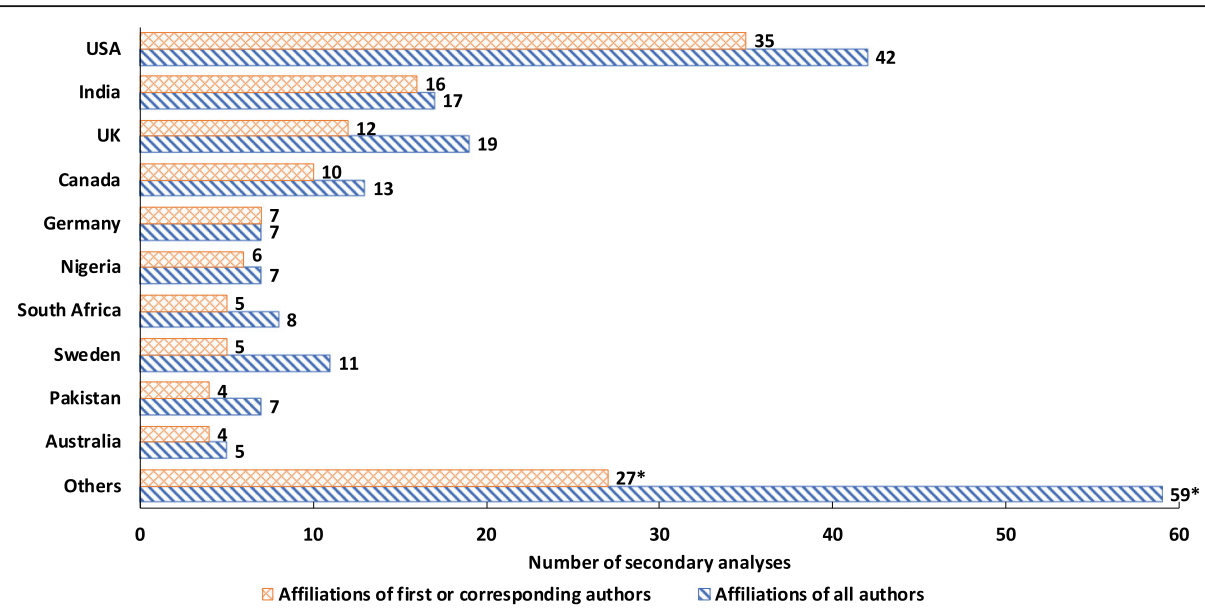

Fig. 4 Distribution of affiliation countries: *Includes international Organizations (WHO, Gavi or UNICEF)(3/11) (affiliations of first or corresponding authors/affiliations of all authors), Brazil(3/4), Bangladesh (3/3), Ethiopia (2/3), Vietnam (2/2), Republic of Senegal (1/2), Burkina Faso (1/4), Uganda (1/3), Switzerland (1/2), Afghanistan (1/1), Belgium (1/1), China (Taiwan) (1/1), Japan (1/1), Nepal (1/1), the Netherlands (1/1), Republic of Korea (1/ 1), Tanzania (1/1), Côte d'Ivoire (1/1), Singapore (1/1), Kenya (1/5), Cameroon (0/2), France (0/2), Cambodia (0/1), Peru (0/1), The Democratic Republic of the Congo (0/1), Zambia (0/1), Zimbabwe (0/1), Republic of the Congo (0/1), Israel (0/1)

immunization managers, these analyses need to be timely and be available to them. Even though DHS and MICS are only conducted in LMICs, most analyses are led by organization outside these countries; the underrepresentation of health researchers from LMICs in the scientific literature has been recently highlighted [135] and the PREPSS initiative has been born to support researchers from LMICs publish in the peer-reviewed international journals [136]. The median time delay between survey and secondary analysis publication was over 5 years. Though we did not explore the delay between survey implementation and report and dataset release by DHS and MICS, this is likely an important factor explaining this lag. Nevertheless, the time delay was worse when an organization in a LMICs contributed to the secondary analysis. Time delays and foreign authors likely reduce the usefulness of the results for immunization programmes and this should make us reflect and strategize on how to facilitate the conduction of secondary analyses immediately after DHS and MICS databases are released, and with the engagement of the country where the survey took place.

Other concerning findings are the fact that many articles did not provide information to assess the limitations of the analyses, for example how persons without documented evidence of vaccination were handled (the validity of recall has been increasingly questioned [137-139]); whether the analysis was adequately weighted; and potential bias. At least, some of these elements seem to be increasingly reported. Finally, only a small proportion of analyses focused on more immunization-specific performance analyses such as timeliness, coverage trends and missed opportunities for vaccination (MOVs), which, in general, cannot be obtained from routine immunization information systems. To support timely, quality and in-country survey immunization analyses, WHO has released a suite of programs, along with detailed documentation, to calculate vaccination coverage survey indicators that go beyond only coverage, in a documented, standardized and replicable manner; these programs are known as the Vaccination Coverage Quality Indicators (VCQI) [137, 140]. Also, several capacity-building activities related to survey analysis are ongoin g[141].

Factors related to diverse immunization outcomes and immunization inequalities were commonly assessed. Inequities are a top priority for the global immunization community and in the human health development agenda, as highlighted by the Immunization Equity Reference Group (ERG) [142], and surveys can help diagnose these issues [143].

Studies exploring inequalities looked into socioeconomic factors and analyzed individual factors such as parental education, religion, urban/rural residence, etc. Overall, the most common factors associated to lower immunization coverage include place of residence, socioeconomic status, maternal education and birth order, but other factors that have been found to affect immunization uptake, such distance to immunization centres, quality of immunization services, behaviour and attitude of health personnel cannot be assessed from DHS and MICS, as they do not collect those variables. Now, research about interventions that will actually decrease inequities and identify and reduce immunization gaps between the privileged and vulnerable populations are still lackin g[144]. Regarding timeliness of vaccination, studies considered a dose timely if the child had 
Table 3 Characterization of secondary analyses by group of affiliation countries ${ }^{\mathrm{a}}$

\begin{tabular}{|c|c|c|c|c|c|c|}
\hline & & \multicolumn{2}{|c|}{$\begin{array}{l}\text { High-income } \\
\text { countries } \\
(N=80)\end{array}$} & \multicolumn{2}{|c|}{$\begin{array}{l}\text { Low-middle income } \\
\text { countries } \\
(N=36)\end{array}$} & \multirow[t]{2}{*}{$\begin{array}{l}P \text { - } \\
\text { value }\end{array}$} \\
\hline & & $\mathrm{n}$ & $\%$ & $\mathrm{n}$ & $\%$ & \\
\hline \multicolumn{7}{|l|}{ Publication metric } \\
\hline \multirow[t]{2}{*}{ Publication year } & 2006-2012 & 20 & 25.0 & 6 & 16.7 & 0.319 \\
\hline & 2012- August 2018 & 60 & 75.0 & 30 & 83.8 & \\
\hline \multirow[t]{2}{*}{ Country analyzed } & Multiple countries & 34 & 42.5 & 3 & 8.3 & $<0.001$ \\
\hline & Single country & 46 & 57.5 & 33 & 91.7 & \\
\hline \multirow[t]{2}{*}{ Survey year } & on or before 2011 & 54 & 67.5 & 30 & 83.3 & 0.078 \\
\hline & 2012-2018 & 26 & 32.5 & 6 & 16.7 & \\
\hline \multirow[t]{3}{*}{ Publishing delay } & Mean (SD) & $4.8(2.2)$ & & $6.6(3.0)$ & & $<0.001$ \\
\hline & Within 5 years & 55 & 68.8 & 11 & 30.6 & $<0.001$ \\
\hline & More than 5 years & 25 & 31.2 & 25 & 69.4 & \\
\hline \multicolumn{7}{|l|}{ Analysis content } \\
\hline \multirow[t]{3}{*}{ Survey types } & DHS & 69 & 86.3 & 31 & 86.1 & 0.979 \\
\hline & MICS & 5 & 6.3 & 2 & 5.6 & \\
\hline & Both & 6 & 7.4 & 3 & 8.3 & \\
\hline \multirow[t]{5}{*}{ Outcomes $^{b}$} & Specific immunization & 47 & 51.1 & 8 & 20.0 & 0.003 \\
\hline & Complete or full immunization & 28 & 30.4 & 25 & 62.5 & \\
\hline & Partly or incomplete immunization & 9 & 9.8 & 3 & 7.5 & \\
\hline & Never vaccinated & 7 & 7.6 & 4 & 10.0 & \\
\hline & Other $^{b}$ & 1 & 1.1 & 0 & 0.0 & \\
\hline \multirow[t]{5}{*}{ Type of analysis } & Factors associated & 53 & 55.8 & 24 & 54.5 & 0.185 \\
\hline & Inequalities & 12 & 12.6 & 9 & 20.5 & \\
\hline & Timeliness & 9 & 9.5 & 3 & 6.8 & \\
\hline & Trends & 9 & 9.5 & 7 & 15.9 & \\
\hline & Others & 12 & 12.6 & 1 & 2.3 & \\
\hline \multicolumn{7}{|l|}{ Analyses quality } \\
\hline \multirow[t]{2}{*}{ Handling of persons without documented vaccination } & Mentioned & 75 & 93.8 & 24 & 66.7 & $<0.001$ \\
\hline & Not mentioned & 5 & 6.2 & 12 & 33.3 & \\
\hline \multirow[t]{2}{*}{ Percentage of card seen } & Mentioned & 27 & 33.8 & 9 & 25.0 & 0.346 \\
\hline & No mentioned & 53 & 66.2 & 27 & 75.0 & \\
\hline \multirow[t]{3}{*}{ Weighted analysis } & Yes & 48 & 60.0 & 19 & 52.8 & 0.807 \\
\hline & No & 3 & 3.8 & 1 & 2.8 & \\
\hline & Not mentioned & 29 & 36.2 & 16 & 44.4 & \\
\hline \multirow[t]{2}{*}{ Potential biases listed } & Yes & 38 & 47.5 & 16 & 44.4 & 0.760 \\
\hline & No & 42 & 52.5 & 20 & 55.6 & \\
\hline \multirow[t]{2}{*}{ Limitation(s) listed } & Yes & 65 & 81.3 & 24 & 66.7 & 0.086 \\
\hline & No & 15 & 18.7 & 12 & 33.3 & \\
\hline
\end{tabular}

${ }^{a}$ Affiliation countries of first and corresponding authors were analysed here. Most of them (110/116) were from the same affiliation or income-level country, for those different $(6 / 116)$ the higher income-level was used for classification

"The one outcome listed as "other" was knowledge about HPV vaccine

received it within a certain timeframe of the recommended age, but definitions varied between studies; this issue has also been noted by other author s[145].
An important limitation in household surveys like DHS and MICS is the unknown magnitude of information bias. DHS and MICS first determine immunization history by documented vaccination, usually by 
transcribing information from the home-based record (HBR) or vaccination card; occasionally they seek vaccination information in health facilities. If documented evidence of vaccination is missing, caregiver's recall is used. Thus, the percentage of immunization records seen and how people without vaccination documentation are handled is important to reflect about the accuracy of the results $[138,139,146]$. In our review, though almost three quarters of the analyses (74.1\%) included recall information of caregiver, $14.6 \%$ did not mention how the results from recall were handled and less than a third (31.0\%) reported the specific percentage of documented vaccination seen, even as this percentage is available in all DHS and MICS reports. Thinking about other limitations of the surveys and the analyses, there is also room for improvement. Only half of analyses were explicit about the potential biases of the survey and close to $40 \%$ of the studies failed to indicate whether the analysis was weighted (as it should be to generalize the results, given the complex sampling design used by DHS and MICS). Not all is bleak; a higher percentage of articles specify bias and limitations after 2012, compared to the earlier period.

Our systematic review has several limitations. We included only DHS and MICS surveys given their standard methods and more availability of their datasets for public use. Thus, nutrition and other multipurpose surveys that also include immunization were not included. Datasets from EPI surveys are rarely made publicly available, limiting the possibility of conducting secondary analyses. Given the limited time to conduct this study, the initial article screening and data extraction were performed only by the first author $(\mathrm{YH})$ with support from the senior one (MCD-H), which may have resulted in excluding relevant articles, and also non-English papers may have been missed. We did not search the EMBASE database because of inaccessibility at WHO, but we searched all 15 related available databases in WHO, especially including databases (LILACS, Popline, African Journals online, IMSEAR, WPRIM) from developing regions of Latin America, Africa, South-East Asia Region, and Western Pacific Region, which benefit the review by increasing the chance of including LMIC publications. We also contacted experts from WHO, Gavi and UNICEF for them to supplement any article we might have missed. Thus, we believe that the thoroughness of the search and review would have minimized this possibility and the main conclusions of this review stand. Further analyses of the types of journals where articles are published was not done. Also, we did not explore whether the metrics analysed have changed following the release of the revised WHO Vaccination Coverage Cluster Survey Manual in 2015 and the suite of supporting materials to conduct analyses beyond coverage thereafter.
Finally, maybe our main limitation is that we did not search the grey literature [147], perhaps analyses done as thesis for university students or country immunization staff, that can potentially be more useful to immunization managers than those reported in the peerreviewed literature.

\section{Conclusion}

We identified over a hundred publications of secondary immunization analyses and characterised them. Most secondary analyses used DHS, rather than MICS, data and more such analyses have been done in recent years. The fact that most authors of these analyses are affiliated with institutions in high-income countries (as opposed to LMICs where these surveys are conducted), the delays between survey implementation and the publication of the analyses, in addition to some incompleteness in reporting some proxies related to the quality of the analyses illustrates that more needs to be done to build capacity to do, and publish, these analyses in LMICs and to make them useful to inform immunization programs. It is now time to better understand country awareness about the conduction of immunization secondary analyses and their use, to promote taking further advantage of the immunization component of DHS and MICS.

\section{Supplementary Information}

The online version contains supplementary material available at https://doi. org/10.1186/s12889-021-10364-0.

\section{Additional file 1: Fig. S1. Summary of DHS and MICS overtime: The grey bars on top of the blue bars refer to unavailable DHS datasets; the green bars on top of the blue bars refer to ongoing or not yet available DHS; the grey bars on top of the orange bars refer to unavailable MICS; the green bars on top of the orange bars refer to ongoing or not yet available MICS. Table S1. Summary of DHS and MICS by year.*. Table S2. Included publications $(n=116)^{*}$.}

\section{Abbreviations}

DHS: The Demographic and Health Survey; MICS: Multiple Indicator Cluster Survey; GIVS: Global Immunization Vision and Strategy; LMICs: Low and middle-income countries; PAHO: Pan American Health Organization; VPD: Vaccine-preventable diseases; GVAP: Global Vaccine Action Plan; SIA: Supplementary Immunization Activity; MOV: Missed Opportunities for Vaccination; VCQI: Vaccination Coverage Quality Indicators; HBR: Home-Based Record

\section{Acknowledgements}

The authors acknowledge the support many colleagues from the regional and headquarters (HQ) level of the Expanded Programme on Immunization, World Health Organization (WHO), especially Marta Gacic-Dobo, Laure Dumolard, Assa Bamogo and Michelle Selim. This work would have not been possible the patience and support from Tom Allen and Jose Garnica from the WHO-HQ library. Thanks to Osama Mere, Viktoriya Hladilova, and Yoann Nédélec who helped us with translation into Arabic, Russian and French, respectively. We also thank Mamadou S. Diallo (UNICEF), Joanna Lowell (DHS) and Turgay Unalay (MICS team UNICEF) for their support, and Felicity Cutts and Dale Rhoda for their many constructive suggestions. Thanks to Samir Sodha for his help proofreading the revised manuscript. Finally, the authors thank the communities that were surveyed and the workers that make possible both, vaccination and surveys worldwide. 


\section{Declaration of interests}

The authors declare that they have no known competing financial interests or personal relationships that could have appeared to influence the work reported in this paper.

\section{Authors' contributions}

Yue Huang: Conceptualization, Data Curation, Writing - Original draft. M. Carolina Danovaro-Holliday: Conceptualization, Writing - Original draft. MCD$\mathrm{H}$ provided guidance with respect to the whole research, including protocol design, methodological guidance, the final decision regarding inclusion on unclear articles and revision of manuscript. YH conducted the literature search, data extraction, data analyses and drafted the manuscript. Both authors read and approved the final manuscript.

\section{Funding}

No specific funding was used for this study. Yue Huang received a scholarship from China scholarship Council (NO. 201806310178) for an internship at WHO. M. Carolina Danovaro[-Holliday] works for the World Health Organization. The authors alone are responsible for the views expressed in this publication and they do not necessarily represent the decisions, policy or views of the World Health Organization.

\section{Availability of data and materials}

Not applicable.

\section{Ethics approval and consent to participate}

Not applicable.

\section{Consent for publication}

Not applicable.

\section{Author details}

'Department of Immunization, Immunization, Analytics and Insights (IAI)، Vaccines and Biologicals (IVB), World Health Organization (WHO), 1211 Geneva, Switzerland. ${ }^{2}$ Present affiliation: State Key Laboratory of Molecular Vaccinology and Molecular Diagnostics, National Institute of Diagnostics and Vaccine Development in Infectious Diseases, Strait Collaborative Innovation Center of Biomedicine and Pharmaceutics, School of Public Health, Xiamen University, Xiamen 361102, China.

Received: 14 March 2020 Accepted: 31 January 2021

\section{Published online: 12 February 2021}

\section{References}

1. Macintosh JLB, Eden LM, Luthy KE, Schouten AE. Global Immunizations: Health Promotion and Disease Prevention Worldwide. MCN Am J Matern Child Nurs. 2017:42(3):139-45.

2. Wallace AS, Ryman TK, Dietz V. Overview of global, regional, and national routine vaccination coverage trends and growth patterns from 1980 to 2009: implications for vaccine-preventable disease eradication and elimination initiatives. J Infect Dis. 2014;210(Suppl 1):S514-22.

3. Burton A, Monasch R, Lautenbach B, Gacic-Dobo M, Neill M, Karimov R, Wolfson L, Jones G, Birmingham M. WHO and UNICEF estimates of national infant immunization coverage: methods and processes. Bull World Health Organ. 2009:87(7):535-41.

4. World Health Organization. Global vaccine action plan 2011-2020. https:// www.who.int/immunization/global_vaccine_action_plan/GVAP_doc_2011_2 020/en/ (Accessed on Mar 14, 2020).

5. World Health Organization. immunization monitoring/data GloballmmunizationData.pdf (Accessed on Mar 14, 2020).

6. Bilous J, Eggers R, Gasse F, Jarrett S, Lydon P, Magan A, Okwo-Bele JM, Salama P, Vandelaer J, Villeneuve $P$, et al. A new global immunisation vision and strategy. Lancet. 2006;367(9521):1464-6.

7. World Health Organization. Meeting of the Strategic Advisory Group of Experts on Immunization, October 2019: conclusions and recommendations. https://apps.who.int/iris/handle/10665/329963 (Accessed on Mar 14, 2020).

8. Hosseinpoor AR, Bergen N, Schlotheuber A, Gacic-Dobo M, Hansen PM, Senouci K, Boerma T, Barros AJD. State of inequality in diphtheria-tetanuspertussis immunisation coverage in low-income and middle-income countries: a multicountry study of household health surveys. Lancet Glob Health. 2016;4(9):e617-26.
9. World Health Organization. Meeting of the Strategic Advisory Group of Experts on Immunization, November 2011 - conclusions and recommendations. https://www.who.int/wer/2012/wer8701.pdf (Accessed on Mar 14, 2020).

10. Cutts FT, Claquin P, Danovaro-Holliday MC, Rhoda DA. Monitoring vaccination coverage: Defining the role of surveys. Vaccine. 2016;34(35): 4103-9.

11. Cutts FT, Claquin P, Danovaro-Holliday MC, Rhoda DA. Reply to comments on Monitoring vaccination coverage: Defining the role of surveys. Vaccine. 2016;34(50):6112-3.

12. Cutts FT, Izurieta HS, Rhoda DA. Measuring coverage in MNCH: design, implementation, and interpretation challenges associated with tracking vaccination coverage using household surveys. PLoS Med. 2013;10(5): e1001404.

13. Pond R, Mounier-Jack S. Comments on "Monitoring vaccination coverage: Defining the role of surveys". Vaccine. 2016;34(50):6111.

14. Henderson RH, Sundaresan T. Cluster Sampling to Assess Immunization Coverage - a Review of Experience with a Simplified Sampling Method. B World Health Organ. 1982;60(2):253-60.

15. United Nations Children's Fund. http:/mics.uniceforg (Accessed on Mar 14, 2020).

16. Demographic and Health Surveys. http://www.measuredhs.com/a boutsurveys/dhs/start.cfm (Accessed on Mar 14, 2020).

17. Gavi.https://www.gavi.org/about/ (Accessed on Mar 14, 2020).

18. The World Bank. World Bank Country and Lending Groups.https://data helpdesk.worldbank.org/knowledgebase/articles/906519-world-bankcountry-and-lending-groups (Accessed on Mar 14, 2020).

19. Demographic and Health Surveys. https://dhsprogram.com/What-We-Do/ Survey-Search.cfm (Accessed on Mar 14, 2020).

20. Meheus F, Van Doorslaer E. Achieving better measles immunization in developing countries: does higher coverage imply lower inequality? Soc Sci Med. 2008;66(8):1709-18.

21. Reynolds HW, Wong EL, Tucker H. Adolescents' use of maternal and child health services in developing countries. Int Fam Plan Perspect. 2006;32(1):6-16.

22. Ntenda PAM, Chuang KY, Tiruneh FN, Chuang YC. Analysis of the effects of individual and community level factors on childhood immunization in Malawi. Vaccine. 2017;35(15):1907-17.

23. Singh L, Rai RK, Singh PK. Assessing the Utilization of Maternal and Child Health Care among Married Adolescent Women: Evidence from India. J Biosoc Sci. 2012;44(1):1-26.

24. Uthman OA, Adedokun ST, Olukade T, Watson S, Adetokunboh O, Adeniran A, Oyetoyan SA, Gidado S, Lawoko S, Wiysonge CS. Children who have received no routine polio vaccines in Nigeria: Who are they and where do they live? Hum Vaccines Immunotherapeutics. 2017;13(9):2111-22.

25. Wagner Z, Szilagyi PG, Sood N. Comparative performance of public and private sector delivery of BCG vaccination: evidence from Sub-Saharan Africa. Vaccine. 2014;32(35):4522-8.

26. Singh A, Singh A, Mahapatra B. The Consequences of Unintended Pregnancy for Maternal and Child Health in Rural India: Evidence from Prospective Data. Matern Child Health J. 2013;17(3):493-500.

27. Oliphant NP, Mason JB, Doherty T, Chopra M, Mann P, Tomlinson M, Nsibande D, Mebrahtu S. The contribution of Child Health Days to improving coverage of periodic interventions in six African countries. Food Nutr Bull. 2010;31(3):S248-63.

28. Canavan ME, Sipsma HL, Kassie GM, Bradley EH. Correlates of complete childhood vaccination in East African countries. PLoS One. 2014:9(4):e95709.

29. Fernandez R, Rammohan A, Awofeso N. Correlates of first dose of measles vaccination delivery and uptake in Indonesia. Asian Pac J Trop Med. 2011; 4(2):140-5.

30. Arsenault C, Johri M, Nandi A, Rodriguez JMM, Hansen PM, Harper S. Country-level predictors of vaccination coverage and inequalities in Gavisupported countries. Vaccine. 2017;35(18):2479-88.

31. Sheikh N, Sultana M, Ali N, Akram R, Mahumud RA, Asaduzzaman M, Sarker AR. Coverage, Timelines, and Determinants of Incomplete Immunization in Bangladesh. Trop Med Infect Dis. 2018;3(3):72.

32. Zaidi SMA, Khowaja S, Dharma VK, Khan AJ, Chandir S. Coverage, timeliness, and determinants of immunization completion in Pakistan Evidence from the Demographic and Health Survey (2006-07). Hum Vaccines Immunotherapeutics. 2014;10(6):1712-20.

33. Van Malderen C, Ogali I, Khasakhala A, Muchiri SN, Sparks C, Van Oyen H, Speybroeck N. Decomposing Kenyan socio-economic inequalities in skilled birth attendance and measles immunization. Int J Equity Health. 2013;12:13. 
34. Latif HM, Ghafoor M, Bajwa R. A Demographic Health Survey to Compare Complete and Incomplete Immunisation in Children Regarding Various Contributing Variables. Indo Am J Pharm Sci. 2018;5(9):8492-500.

35. Fernandez RC, Awofeso N, Rammohan A. Determinants of apparent ruralurban differentials in measles vaccination uptake in Indonesia. Rural Remote Health. 2011;11(3):1702

36. Pandey S, Lee HN. Determinants of child immunization in Nepal: The role of women's empowerment. Health Educ J. 2012;71(6):642-53.

37. Akmatov MK, Kretzschmar M, Kramer A, Mikolajczyk RT. Determinants of childhood vaccination coverage in Kazakhstan in a period of societal change: Implications for vaccination policies. Vaccine. 2007; 25(10):1756-63.

38. Mbengue MAS, Sarr M, Faye A, Badiane O, Camara FBN, Mboup S, Dieye TN. Determinants of complete immunization among senegalese children aged 12-23 months: evidence from the demographic and health survey. BMC Public Health. 2017;17:9.

39. Herliana P, Douiri A. Determinants of immunisation coverage of children aged 12-59 months in Indonesia: a cross-sectional study. BMJ Open. 2017; 7(12):14.

40. Haile ZT, Chertok IRA, Teweldeberhan AK. Determinants of Utilization of Sufficient Tetanus Toxoid Immunization During Pregnancy: Evidence from the Kenya Demographic and Health Survey, 2008-2009. J Community Health. 2013;38(3):492-9.

41. Prusty RK, Keshri K. Differentials in child nutrition and immunization among migrants and non-migrants in Urban India. Int J Migr Health Soc Care. 2015; 11(3):194-205.

42. Rossi R. Do Maternal Living Arrangements Influence the Vaccination Status of Children Age 12-23 Months? A Data Analysis of Demographic Health Surveys 2010-11 from Zimbabwe. PLoS One. 2015;10(7):e0132357.

43. Lu C, Michaud CM, Gakidou E, Khan K, Murray CJL. Effect of the Global Alliance for Vaccines and Immunisation on diphtheria, tetanus, and pertussis vaccine coverage: an independent assessment. Lancet. 2006;368(North American Edition(9541)):1088-95.

44. Afzal S, Naeem A, Shahid U, Syed WN, Khan U, Zaidi NM. Effective role of lady health workers in immunization of children in Pakistan. Pak J Med Sci. 2016;32(6):1500-5.

45. Kawakatsu Y, Tanaka J, Ogawa K, Ogendo K, Honda S. Effects of three interventions and determinants of full vaccination among children aged 12 59 months in Nyanza province, Kenya. Public Health. 2015;129(11):1530-8.

46. Hanson CM, Mirza I, Kumapley R, Ogbuanu I, Kezaala R, Nandy R. Enhancing immunization during second year of life by reducing missed opportunities for vaccinations in 46 countries. Vaccine. 2018;36(23):3260-8.

47. Anand A, Pallansch MA, Estivariz CF, Gary H, Wassilak SGF. Estimating the Likely Coverage of Inactivated Poliovirus Vaccine in Routine Immunization: Evidence From Demographic and Health Surveys. J Infect Dis. 2014;210:S465-74.

48. Akmatov MK, Kimani-Murage E, Pessler F, Guzman CA, Krause G, Kreienbrock L. Mikolajczyk RT. Evaluation of invalid vaccine doses in 31 countries of the WHO African Region. Vaccine. 2015;33(7):892-901.

49. World Health Orgnization. Explorations of inequality: childhood immunization. 2018.

50. Rahman M, Obaida-Nasrin S. Factors affecting acceptance of complete immunization coverage of children under five years in rural Bangladesh. Salud Publica Mex. 2010;52(2):134-40.

51. Bugvi AS, Rahat R, Zakar R, Zakar MZ, Fischer F, Nasrullah M, Manawar R. Factors associated with non-utilization of child immunization in Pakistan: evidence from the Demographic and Health Survey 2006-07. BMC Public Health. 2014;14:232.

52. Bbaale E. Factors influencing childhood immunization in Uganda. Health Popul Nutr. 2013;31(1):118-29.

53. Lakew $Y$, Bekele A, Biadgilign S. Factors influencing full immunization coverage among 12-23 months of age children in Ethiopia: evidence from the national demographic and health survey in 2011. BMC Public Health. 2015;15:8.

54. Tsawe M, Moto A, Netshivhera T, Ralesego L, Nyathi C, Susuman AS. Factors influencing the use of maternal healthcare services and childhood immunization in Swaziland. Int J Equity Health. 2015:14:11.

55. Antai D. Faith and child survival: the role of religion in childhood immunization in Nigeria. J Biosoc Sci. 2009;41(1):57-76.

56. Antai D. Gender inequities, relationship power, and childhood immunization uptake in Nigeria: a population-based cross-sectional study. Int J Infect Dis. 2012;16(2):E136-45.
57. Corsi DJ, Bassani DG, Kumar R, Awasthi S, Jotkar R, Kaur N, Jha P. Gender inequity and age-appropriate immunization coverage in India from 1992 to 2006. BMC Int Health Hum Rights. 2009:9(Suppl 1):S3.

58. Takahashi S, Metcalf CJE, Ferrari MJ, Tatem AJ, Lessler J. The geography of measles vaccination in the African Great Lakes region. Nat Commun. 2017;8:9.

59. Ebot JO. "Girl Power!": The Relationship between Women's Autonomy and Children's Immunization Coverage in Ethiopia. J Health Popul Nutr. 2015;33:18.

60. Anand S, Barnighausen T. Health workers and vaccination coverage in developing countries: an econometric analysis. Lancet. 2007;369(9569):1277-85.

61. Schweitzer A, Akmatov MK, Krause G. Hepatitis B vaccination timing: results from demographic health surveys in 47 countries. B World Health Organ. 2017;95(3):199-209.

62. Haddad S, Bicaba A, Feletto M, Fournier P, Zunzunegui MV. Heterogeneity in the validity of administrative-based estimates of immunization coverage across health districts in Burkina Faso: implications for measurement, monitoring and planning. Health Policy Plan. 2010;25(5):393-405.

63. Utazi CE, Thorley J, Alegana VA, Ferrari MJ, Takahasi S, Jessica C, Metcalf E, Lessler J, Tatem AJ. High resolution age-structured mapping of childhood vaccination coverage in low and middle income countries. Vaccine. 2018; 36(12):1583-91.

64. Victora CG, Barros AJD, Axelson H, Bhutta ZA, Chopra M, Franca GVA, Kerber K, Kirkwood BR, Newby H, Ronsmans C, et al. How changes in coverage affect equity in maternal and child health interventions in 35 Countdown to 2015 countries: an analysis of national surveys. Lancet. 2012;380(9848):114956.

65. Bondy JN, Thind A, Koval JJ, Speechley KN. Identifying the determinants of childhood immunization in the Philippines. Vaccine. 2009;27(1):169-75.

66. Berk J, Adhvaryu A. The impact of a novel franchise clinic network on access to medicines and vaccinations in Kenya: a cross-sectional study. BMJ Open. 2012;2(4):7.

67. Postolovska I, Helleringer S, Kruk ME, Verguet S. Impact of measles supplementary immunisation activities on utilisation of maternal and child health services in low-income and middle-income countries. BMJ Glob Health. 2018;3(3):10.

68. Portnoy A, Jit M, Helleringer S, Verguet S. Impact of measles supplementary immunization activities on reaching children missed by routine programs. Vaccine. 2018;36(1):170-8.

69. Schweitzer A, Pessler F, Akmatov MK. Impact of rotavirus vaccination on coverage and timing of pentavalent vaccination - Experience from 2 Latin American countries. Hum Vaccines Immunotherapeutics. 2016;12(5):1250-6.

70. Cetorelli $V$. The impact of the Iraq War on neonatal polio immunisation coverage: a quasi-experimental study. J Epidemiol Community Health. 2015; 69(3):226-31.

71. Schweitzer A, Krause G, Pessler F, Akmatov MK. Improved coverage and timing of childhood vaccinations in two post-Soviet countries, Armenia and Kyrgyzstan. BMC Public Health. 2015;15:9.

72. Adedokun ST, Uthman OA, Adekanmbi VT, Wiysonge CS. Incomplete childhood immunization in Nigeria: a multilevel analysis of individual and contextual factors. BMC Public Health. 2017:17(1):236.

73. Ashish KC, Nelin V, Raaijmakers H, Kim HJ, Singh C, Malqvist M. Increased immunization coverage addresses the equity gap in Nepal. B World Health Organ. 2017;95(4):261-9.

74. McGlynn N, Wilk P, Luginaah I, Ryan BL, Thind A. Increased use of recommended maternal health care as a determinant of immunization and appropriate care for fever and diarrhoea in Ghana: an analysis pooling three demographic and health surveys. Health Policy Plan. 2015;30(7):895-905.

75. Abadura SA, Lerebo WT, Kulkarni U, Mekonnen ZA. Individual and community level determinants of childhood full immunization in Ethiopia: a multilevel analysis. BMC Public Health. 2015;15:972.

76. Wiysonge CS, Uthman OA, Ndumbe PM, Hussey GD. Individual and Contextual Factors Associated with Low Childhood Immunisation Coverage in Sub-Saharan Africa: A Multilevel Analysis. PLoS One. 2012;7(5):7.

77. Restrepo-Mendez MC, Barros AJD, Wong KLM, Johnson HL, Pariyo G, Franca GVA, Wehrmeister FC, Victora CG. Inequalities in full immunization coverage: trends in low- and middle-income countries. B World Health Organ. 2016; 94(11):794-805.

78. Antai D. Inequitable childhood immunization uptake in Nigeria: a multilevel analysis of individual and contextual determinants. BMC Infect Dis. 2009;9: 10.

79. Kumar A, Ram F. Influence of family structure on child health: evidence from India. J Biosoc Sci. 2013;45(5):577-99. 
80. Abuya BA, Onsomu EO, Kimani JK, Moore D. Influence of Maternal Education on Child Immunization and Stunting in Kenya. Matern Child Health J. 2011;15(8):1389-99.

81. Singh PK. Parasuraman S: 'Looking beyond the male-female dichotomy' sibling composition and child immunization in India, 1992-2006. Soc Sci Med. 1982;2014(107):145-53.

82. Singh K, Haney E, Olorunsaiye C. Maternal Autonomy and Attitudes Towards Gender Norms: Associations with Childhood Immunization in Nigeria. Matern Child Health J. 2013;17(5):837-41.

83. Malhotra C, Malhotra R, Ostbye T, Subramanian SV. Maternal autonomy and child health care utilization in India: results from the National Family Health Survey. Asia Pac J Public Health. 2014;26(4):401-13.

84. Onsomu EO, Abuya BA, Okech IN, Moore D, Collins-McNeil J. Maternal Education and Immunization Status Among Children in Kenya. Matern Child Health J. 2015:19(8):1724-33.

85. Khan MT, Zaheer S, Shafique K. Maternal education, empowerment, economic status and child polio vaccination uptake in Pakistan: a population based cross sectional study. BMJ Open. 2017;7(3):7.

86. Smith-Greenaway E, Madhavan S. Maternal migration and child health: An analysis of disruption and adaptation processes in Benin. Soc Sci Res. 2015; 54:146-58.

87. Lessler J, Metcalf CJE, Grais RF, Luquero FJ, Cummings DAT, Grenfell BT. Measuring the Performance of Vaccination Programs Using Cross-Sectional Surveys: A Likelihood Framework and Retrospective Analysis. PLoS Med. 2011;8(10):10.

88. Antai D. Migration and child immunization in Nigeria: individual- and community-level contexts. BMC Public Health. 2010;10:116.

89. Restrepo-Mendez MC, Barros AJ, Wong KL, Johnson HL, Pariyo G, Wehrmeister FC, Victora CG. Missed opportunities in full immunization coverage: findings from low- and lower-middle-income countries. Glob Health Action. 2016;9:30963.

90. Arsenault C, Harper S, Nandi A, Rodriguez JMM, Hansen PM, Johri M Monitoring equity in vaccination coverage: A systematic analysis of demographic and health surveys from 45 Gavi-supported countries. Vaccine. 2017;35(6):951-9

91. Bicaba A, Haddad S, Kabore M, Taminy E, Feletto M, Fournier P. Monitoring the performance of the Expanded Program on Immunization: the case of Burkina Faso. BMC Int Health Hum Rights. 2009;9:9.

92. Adegboye OA, Kotze D, Adegboye OA. Multi-year trend analysis of childhood immunization uptake and coverage in Nigeria. J Biosoc Sci. 2014; 46(2):225-39.

93. Chandran SA, Ramachandra SS, Sekhar PS. National Family Health Survey-3 reported low full-immunization coverage rates in Andhra Pradesh, India: who is to be blamed? J Public Health (Oxford, England). 2011;33(4):489-95

94. Hajizadeh M, Heymann J, Strumpf E, Harper S, Nandi A. Paid maternity leave and childhood vaccination uptake: Longitudinal evidence from 20 low-andmiddle-income countries. Soc Sci Med. 1982;2015(140):104-17.

95. Rammohan A, Awofeso N, Fernandez RC. Paternal education status significantly influences infants' measles vaccination uptake, independent of maternal education status. BMC Public Health. 2012;12:336.

96. Helleringer S, Abdelwahab J, Vandenent M. Polio supplementary immunization activities and equity in access to vaccination: evidence from the demographic and health surveys. J Infect Dis. 2014;210(Suppl 1):S531-9.

97. Bermedo-Carrasco S, Feng CX, Pena-Sanchez JN, Lepnurm R. Predictors of having heard about human papillomavirus vaccination: Critical aspects for cervical cancer prevention among Colombian women. Gac Sanit. 2015;29(2): $112-7$.

98. Landoh DE, Ouro-Kavalah F, Yaya I, Kahn AL, Wasswa P, Lacle A, Nassoury DI, Gitta SN, Soura AB. Predictors of incomplete immunization coverage among one to five years old children in Togo. BMC Public Health. 2016;16:7.

99. Dionne-Odom J, Westfall AO, Nzuobontane D, Vinikoor MJ, Halle-Ekane G, Welty T, Tita ATN. Predictors of Infant Hepatitis B Immunization in Cameroon: Data to Inform Implementation of a Hepatitis B Birth Dose Pediatr Infect Dis J. 2018;37(1):103-7.

100. Ashbaugh HR, Hoff NA, Doshi RH, Alfonso VH, Gadoth A, Mukadi P, OkitolondaWemakoy E, Muyembe-Tamfum JJ, Gerber SK, Cherry JD, et al. Predictors of measles vaccination coverage among children 6-59 months co of age in the Democratic Republic of the Congo. Vaccine. 2018;36(4):587-93.

101. Kols A, Gorar Z, Sharjeel M, Midhet F, Nazir R, Kumar D, Fareed A. Provincial differences in levels, trends, and determinants of childhood immunization in Pakistan. East Mediterr Health J. 2018;24(4):333-44.
102. Sia D, Fournier P, Kobiane JF, Sondo BK. Rates of coverage and determinants of complete vaccination of children in rural areas of Burkina Faso (1998-2003). BMC Public Health. 2009;9:10.

103. Moyer $C A$, Tadesse $L$, Fisseha $S$. The relationship between facility delivery and infant immunization in Ethiopia. Int J Gynecol Obstet. 2013;123(3):217-20.

104. Patel MM, Clark AD, Sanderson CFB, Tate J, Parashar UD. Removing the Age Restrictions for Rotavirus Vaccination: A Benefit-Risk Modeling Analysis. PLoS Med. 2012;9(10):13.

105. Imran H, Raja D, Grassly NC, Wadood MZ, Safdar RM, O'Reilly KM. Routine immunization in Pakistan: comparison of multiple data sources and identification of factors associated with vaccination. Int Health. 2018;10(2):84-91.

106. Tao WJ, Petzold M, Forsberg BC. Routine vaccination coverage in low- and middle-income countries: further arguments for accelerating support to child vaccination services. Glob Health Action. 2013;6:1-8.

107. Singh PK, Parsuraman S. Sibling composition and child immunization in India and Pakistan, 1990-2007. World J Pediatr. 2014;10(2):145-50

108. Clouston S, Kidman R, Palermo T. Social inequalities in vaccination uptake among children aged 0-59 months living in Madagascar: an analysis of Demographic and Health Survey data from 2008 to 2009. Vaccine. 2014; 32(28):3533-9.

109. Joe W, Mishra US, Navaneetham K. Socio-economic inequalities in child health: recent evidence from India. Global Public Health. 2010;5(5):493-508.

110. Douba A, Aka LBN, Yao GHA, Zengbe-Acray P, Akani BC, Konan N. Sociodemographic factors associated with incomplete immunization of children aged 12 to 59 months in six West African countries. Sante Publique. 2015;27(4):575-84.

111. Zuhair M, Roy RB. Socioeconomic Determinants of the Utilization of Antenatal Care and Child Vaccination in India. Asia Pac J Public Health. 2017;29(8):649-59.

112. Kumar C, Singh PK, Singh L, Rai RK. Socioeconomic disparities in coverage of full immunisation among children of adolescent mothers in India, 19902006: a repeated cross-sectional analysis. BMJ Open. 2016:6(8):e009768.

113. Prusty RK, Kumar A. Socioeconomic dynamics of gender disparity in childhood immunization in India, 1992-2006. PLoS One. 2014;9(8):e104598.

114. Boulton ML, Carlson BF, Power LE, Wagner AL. Socioeconomic factors associated with full childhood vaccination in Bangladesh, 2014. Int J Infect Dis. 2018;69:35-40

115. Brownwright TK, Dodson ZM, van Panhuis WG. Spatial clustering of measles vaccination coverage among children in sub-Saharan Africa. BMC Public Health. 2017:17(1):957.

116. Chima CC, Franzini L. Spillover effect of HIV-specific foreign aid on immunization services in Nigeria. Int Health. 2016;8(2):108-15.

117. Dixit P, Dwivedi LK, Ram F. Strategies to Improve Child Immunization via Antenatal Care Visits in India: A Propensity Score Matching Analysis. PLoS One. 2013:8(6):e66175.

118. Rahman M. Tetanus toxoid vaccination coverage and differential between urban and rural areas of Bangladesh. East Afr J Public Health. 2009;6(1):26-31.

119. Akmatov MK, Mikolajczyk RT. Timeliness of childhood vaccinations in 31 low and middle-income countries. J Epidemiol Community Health. 2012;66(7):e14.

120. An DTM, Lee JK, Minh HV, Trang NTH, Huong NTT, Nam YS, Dung DV. Timely immunization completion among children in Vietnam from 2000 to 2011: a multilevel analysis of individual and contextual factors. Glob Health Action. 2016:9:38-48

121. Clark A, Sanderson C. Timing of children's vaccinations in 45 low-income and middle-income countries: an analysis of survey data. Lancet. 2009; 373(9674):1543-9.

122. Metcalf CJE, Tatem A, Bjornstad ON, Lessler J, O'Reilly K, Takahashi S, Cutts F, Grenfell BT. Transport networks and inequities in vaccination: remoteness shapes measles vaccine coverage and prospects for elimination across Africa. Epidemiol Infect. 2015;143(7):1457-66.

123. Hong R, Chhea V. Trend and Inequality in Immunization Dropout Among Young Children in Cambodia. Matern Child Health J. 2010;14(3):446-52.

124. Ushie BA, Fayehun OA, Ugal DB. Trends and patterns of under-5 vaccination in Nigeria, 1990-2008: what manner of progress? Child Care Health Dev. 2014;40(2):267-74

125. Singh PK. Trends in Child Immunization across Geographical Regions in India: Focus on Urban-Rural and Gender Differentials. PLoS One. 2013;8(9): e73102.

126. Kien VD, Minh HV, Giang KB, Mai VQ, Tuan NT, Quam MB. Trends in childhood measles vaccination highlight socioeconomic inequalities in Vietnam. Int J Public Health. 2017;62:S41-9. 
127. Semali IA. Trends in immunization completion and disparities in the context of health reforms: the case study of Tanzania. BMC Health Serv Res. 2010;10:299.

128. Bosch-Capblanch X, Banerjee K, Burton A. Unvaccinated children in years of increasing coverage: how many and who are they? Evidence from 96 lowand middle-income countries. Tropical Med Int Health. 2012;17(6):697-710.

129. Prakash R, Kumar A. Urban poverty and utilization of maternal and child health care services in India. J Biosoc Sci. 2013;45(4):433-49.

130. Mbengue MAS, Mboup A, Ly ID, Faye A, Camara FBN, Thiam M, Ndiaye BP, Dieye TN, Mboup S. Vaccination coverage and immunization timeliness among children aged 12-23 months in Senegal: a Kaplan-Meier and Cox regression analysis approach. Pan Afr Med J. 2017;27(Suppl 3):8.

131. Masters NB, Wagner AL, Carlson BF, Boulton ML. Vaccination timeliness and co-administration among Kenyan children. Vaccine. 2018;36(11):1353-60.

132. Kriss JL, Goodson J, Machekanyanga Z, Shibeshi ME, Daniel F, Masresha B, Kaiser $R$. Vaccine receipt and vaccine card availability among children of the Apostolic faith: analysis from the 2010-2011 Zimbabwe demographic and health survey. Pan Afr Med J. 2016;24:10.

133. Sahu D, Pradhan J, Jayachandran V, Khan N. Why immunization coverage fails to catch up in India? A community-based analysis. Child Care Health Dev. 2010;36(3):332-9.

134. Echaiz J, Blas M, Kancherla V. Unintended pregnancy and its impact on childhood rotavirus immunization in Peru. Rev Panam Salud Pública. 2018;42:e96.

135. Hedt-Gauthier BL, Jeufack HM, Neufeld NH, Alem A, Sauer S, Odhiambo J, Boum Y, Shuchman M, Volmink J. Stuck in the middle: a systematic review of authorship in collaborative health research in Africa, 2014-2016. BMJ Glob Health. 2019:4(5):e001853.

136. Busse C, August E. Addressing power imbalances in global health: PrePublication Support Services (PREPSS) for authors in low-income and middle-income countries. BMJ Glob Health. 2020;5(2):e002323.

137. Danovaro-Holliday MC, Dansereau E, Rhoda DA, Brown DW, Cutts FT, GacicDobo M. Collecting and using reliable vaccination coverage survey estimates: Summary and recommendations from the "Meeting to share lessons learnt from the roll-out of the updated WHO Vaccination Coverage Cluster Survey Reference Manual and to set an operational research agenda around vaccination coverage surveys", Geneva, 18-21 April 2017. Vaccine. 2018:36(34):5150-9.

138. Modi RN, King C, Bar-Zeev N, Colbourn T. Caregiver recall in childhood vaccination surveys: Systematic review of recall quality and use in low- and middle-income settings. Vaccine. 2018;36(29):4161-70.

139. Dansereau E, Brown D, Stashko L, Danovaro-Holliday MC. A systematic review of the agreement of recall, home-based records, facility records, BCG scar, and serology for ascertaining vaccination status in low and middleincome countries [version 1; peer review: 1 approved, 1 approved with reservations]. Gates Open Res. 2019;3(923).

140. VCQI Resources; n.d. http://www.biostatglobal.com/NCQI_resources.html (Accessed on Mar 14, 2020).

141. Global Immunization Newsletter.https://www.who.int/immunization/gin/en/ (Accessed on Mar 14, 2020).

142. World Health Organization. Addressing the persistent inequities in immunization coverage. https://www.who.int/bulletin/volumes/98/2/19-241 620.pdf (Accessed on Mar 14, 2020).

143. World Health Organization. Global Health Observatory (GHO) data. State of inequality: childhood immunization. https://www.who.int/gho/health_ equity/report_2016_immunization/en/ (Accessed on Mar 14, 2020).

144. Bosch-Capblanch X, Zuske MK, Auer C. Research on subgroups is not research on equity attributes: Evidence from an overview of systematic reviews on vaccination. Int J Equity Health. 2017;16(1):95.

145. Masters NB, Wagner AL, Boulton ML. Vaccination timeliness and delay in low- and middle-income countries: a systematic review of the literature, 2007-2017. Hum Vaccin Immunother. 2019;15(12):2790-805.

146. Zuhair M, Smit GSA, Wallis G, Jabbar F, Smith C, Devleesschauwer B, Griffiths P. Estimation of the worldwide seroprevalence of cytomegalovirus: a systematic review and meta-analysis. Rev Med Virol. 2019;29(3):e2034.

147. Mahood Q, Van Eerd D, Irvin E. Searching for grey literature for systematic reviews: challenges and benefits. Res Synth Methods. 2014;5(3):221-34.

\section{Publisher's Note}

Springer Nature remains neutral with regard to jurisdictional claims in published maps and institutional affiliations.

Ready to submit your research? Choose BMC and benefit from:

- fast, convenient online submission

- thorough peer review by experienced researchers in your field

- rapid publication on acceptance

- support for research data, including large and complex data types

- gold Open Access which fosters wider collaboration and increased citations

- maximum visibility for your research: over $100 \mathrm{M}$ website views per year

At BMC, research is always in progress.

Learn more biomedcentral.com/submissions 